\title{
Detecting Asymmetric Price Transmission with Consistent Threshold along the Fish Supply Chain
}

\author{
Michel Simioni, ${ }^{1}$ Frédéric Gonzales, ${ }^{2}$ Patrice Guillotreau ${ }^{3}$ \\ and Laurent Le Grel ${ }^{4}$
}
${ }^{1}$ Toulouse School of Economics, INRA-GREMAQ, 21 Allées de Brienne, 31015 Toulouse Cedex 6 (phone: +3305611286 00; fax: +33056112 86 86; e-mail:simioni@toulouse-inra.fr).
${ }^{2}$ OECD, 2, rue André Pascal, 75775 Paris Cedex 16, France (phone: +33 1452482 00; fax : +33 1452485 00; e-mail: Frederic.Gonzales@oecd.org).
${ }^{3}$ LEMNA, Université de Nantes, IEMN-IAE, Chemin de la Censive du Tertre, BP 52231, 44322 Nantes Cedex 3, France (corresponding author: phone: +33 2401417 46; fax: +332401417 00; e-mail: patrice.guillotreau@univ-nantes.fr).
${ }^{4}$ LEMNA, Université de Nantes, IEMN-IAE, Chemin de la Censive du Tertre, BP 52231, 44322 Nantes Cedex 3, France (phone: +33 2401417 46; fax: +33 2401417 00; e-mail: laurent.legrel@univ-nantes.fr).

\begin{abstract}
The present study deals with asymmetric price transmission (APT) along the fish value chain by using a consistent threshold autoregressive (consistent TAR and momentum-threshold autoregressive [M-TAR]) model. A nonzero threshold captures strategic behaviors and adjustment costs that are not observable with small price changes around a zero threshold. Fish farming, because of greater control over supply, is expected to produce less asymmetry than wild harvesting. Asymmetry is notwithstanding found for both wild cod and farmed salmon marketed in France, but only with consistent thresholds and operating in opposite ways. The results are discussed with regard to the trade restrictions imposed by the Common Fisheries Policy.
\end{abstract}

Cet article traite de l'asymétrie de transmission des prix (ATP) dans la filière des produits de la mer en utilisant un modèle autorégressif à effet de seuil (consistent TAR et M-TAR). Un seuil non nul permet de révéler certains comportements stratégiques et des coûts fixes d'ajustement qui ne seraient pas observables sur de faibles variations de prix autour d'un seuil nul. On s'attend à ce que l'aquaculture, en vertu d'un degré de contrôle supérieur sur l'offre, engendre une plus faible asymétrie comparativement à la production halieutique. Une asymétrie de transmission est néanmoins observée à la fois dans le cas du cabillaud sauvage et du saumon d'élevage commercialisés en France, mais uniquement à partir de seuils endogènes et l'ATP agissant en sens opposé. Les résultats sont commentés au regard des restrictions commerciales imposés par la Politique Commune des Pêches européenne.

\section{INTRODUCTION}

The issue of asymmetric price transmission (APT) has been analyzed by agricultural economists for a very long time as it represents a case of market failure in microeconomic theory. Any exogenous shock to the price system, either coming from the supply or the demand side, should result in symmetric adjustments to the long-run market equilibrium, whether the price shock is negative or positive. Various empirical or theoretical reasons 
are proposed to explain a differentiated adjustment of the consumer price according to the sign of the ex-farm price change. In recent studies, it is admitted that an asymmetric transmission would either stem from adjustment costs - such as menu costs - or from a strategic behavior of the intermediaries. In particular, the big multiple retailers would be more reluctant to transmit a price decrease of the primary product than a price increase to the consumer. Such asymmetry might create distortion in the transmission of information down the marketing chain, hence giving some evidence of market power. The final price does not equal the market clearing price, and primary production could be temporarily in excess.

The adjustment costs, although acknowledged as important barriers to perfect transmission in the food value chains, are rarely measured as such in the literature. The threshold and momentum-threshold autoregressive (TAR and M-TAR) models provide perhaps the most reliable methodology to deal with this appraisal when using nonstationary time series. However, these methods are mostly used with a zero threshold that may not be the most appropriate value in the case of modern distribution practices. Our contribution uses a more consistent threshold to look at food markets whose asymmetric patterns can only be observed whenever the price change of the primary product exceeds a certain limit. Below this limit, adjustment costs would not be covered by the benefits of a faster transmission and retail prices are adjusted symmetrically as a routine. Beyond the threshold, the adjustment behavior might be different because the margin is lastingly affected.

This paper looks at two different fish supply chains in France (farmed Atlantic salmon [Salmo salar] and wild-harvested North Atlantic cod [Gadus morhua]) passing through the single outlet of supermarket chains. The marketing behaviors are expected to be different in the two chains because the control over production is greater in the case of fish farming. Adjustment costs being higher for fish harvesting, they are assumed to produce more asymmetric results than farmed products. The regulations adopted within the EU Common Fisheries Policy (CFP) framework affect both the supply of wildcaught fish (total allowable catch [TAC] and quota) and farmed fish (minimum import prices [MIPs] and other trade restrictions for the Norwegian farmed Atlantic salmon). As a result, inelastic supply may increase the adjustment costs of the intermediaries and produce APT down the chain.

The second section introduces a brief overview of the theoretical and empirical background of APT. The third one gives some industrial features and data on the fishing industry used in this study. The methodology and empirical results are developed in the fourth and fifth sections, before the discussion in the last section.

\section{THE ANALYSIS OF ASYMMETRIC PRICE TRANSMISSION}

Microeconomic theory predicts that any external shock to the demand or supply side of a market, whatever the number of stages between producers and consumers, should not result in a different speed (or length) of adjustment to the long-run equilibrium according to the sign of the variation. Any significant difference would reveal a case of market failure as long as the output price is expected to respond symmetrically to variations of input prices. In that respect, both elasticity of derived demand and consumer price elasticity should be equal (Wohlgenant 2001). Various explanations of lead lag relations between different levels of the chain are given in the literature (for a review of the APT literature, see for instance Meyer and von Cramon-Taubadel 2004; Frey and Manera 2007). Heien 
(1980) and Worth (1999) note that repricing may be costly due to the time requested to put on new labels (namely the menu costs), and to the loss of goodwill from the consumers who prefer stable prices. Heien points out the importance of storage in price transmission and Wohlgenant (1985) has also shown that inventory holding by retailers can explain for a large part the delay in the price pass-through between wholesale and retail. There is also a common feeling that market power is used by stakeholders to pass a cost increase more rapidly on to the next stage whereas they will delay the transmission of a cost decrease. This may result in market inefficiencies and suboptimal resource allocation. Indeed, asymmetry in the vertical transmission of prices is generally considered as a sign of collusive behavior (Carlton 1989; Azzam 1999). Such a suspicion stems from the observation in the European food markets that the downstream industries are more concentrated than the primary ones. Nevertheless, Eckert (2002) shows that asymmetry can also be the consequence of a price war, with alternating phases of declines and sharp increases, after which the price has reached such a low level that it is not worthwhile for a firm to look for a larger market share by setting a lower price. Azzam (1999) also considers that a competitive retail sector is not incompatible with asymmetry insofar as spatially competitors face concave spatial demand functions. Bailey and Brorsen (1989) have demonstrated that a kinked demand curve could lead to asymmetric responses. Finally, Griffith and Piggott (1994), in their study of the Australian three-stage chain for beef, lamb, and pork meat, indicate the presence of asymmetry in some of the tested markets, but not in the pork market where there is a higher degree of concentration and high cross-price elasticities with the lamb and beef markets where asymmetry was found. On the basis of previous results, the link between asymmetric adjustment and market power is far from being clearly demonstrated.

Other explanations can be found in the literature. For Kinnucan and Forker (1987), public intervention on markets can be a source of asymmetry. In particular, floor price policies on farm products, aimed at protecting producers' income for a period, may reduce the uncertainty surrounding the interpretation of cost changes. An increase due to the implementation of a floor price is more likely to be interpreted as permanent and transmitted more rapidly by the middlemen than a decrease which is perceived as a transitory change. Ward (1982) does not provide any reason for the asymmetry found on a three-stage chain for fresh vegetables, but he notes that the perishable nature of products may be a partial explanation because "rising prices could reduce retail sales and increase the incidence of spoilage" (Ward 1982, p. 210). Retailers would then delay the transmission of upstream price increases because they fear not to be able to sell the full stock. The risk dimension has also been introduced in the analysis by Brorsen et al (1985). Our contribution discusses the threshold above or below which APT may appear. Implicitly, the literature refers to a zero threshold, from which positive and negative shocks on the supply side are differentially transmitted to the demand side. The present paper introduces consistent thresholds which may reveal APT although not visible with a zero threshold. We assume that producers may face difficulties to adjust the supply levels to the frequent and successive shifts of demand, in particular for those fresh products for which inventories are not always possible. Uncertainty affecting the supply conditions is the rule rather than the exception, making expectations and adjustments more chaotic on the supply side. Such conditions are particularly present in the fishing industry due to the environmental conditions surrounding the exploitation of wild-caught and common-pool resources. The catch levels fluctuate to a great extent from one period 
Table 1. Supermarket sales of fresh fish in 1998

\begin{tabular}{cccc}
\hline & Whole fish & Steaks and fillets & Total \\
\hline Cod & & & \\
Qty & $1,269 \mathrm{mt}$ & $8,448 \mathrm{mt}$ & $9,717 \mathrm{mt}$ \\
Val & $9,786 \times 10^{3}$ euro & $76,733 \times 10^{3}$ euro & $80,411 \times 10^{3}$ euro \\
Pr. & 7.71 euro $/ \mathrm{kg}$ & $9.08 \mathrm{euro} / \mathrm{kg}$ & $8.28 \mathrm{euro} / \mathrm{kg}$ \\
Salmon & & & \\
Qty & $6,752 \mathrm{mt}$ & $11,486 \mathrm{mt}$ & $18,238 \mathrm{mt}$ \\
Val & $35,706.10^{3}$ euro & $115,880.10^{3}$ euro & $163,432.10^{3}$ euro \\
Pr. & 5.29 euro $/ \mathrm{kg}$ & 10.09 euro $/ \mathrm{kg}$ & 8.96 euro $/ \mathrm{kg}$ \\
\hline
\end{tabular}

Source: FranceAgrimer (http://www.franceagrimer.fr/).

Note: $\mathrm{mt}$, metric tonnes.

to another, thus affecting the whole organization along the marketing chain. For the last two decades, control over fish farming production has substantially contributed to reduce the variability of the fish supply, and fits better with modern retailing facilities. The farmed or wild-harvested origin of the products results in different elasticities of supply because adjustment is easier when the fish can be slaughtered at chosen periods of time. As a consequence, it seems interesting to investigate the relationship between the characteristics of supply (farmed or wild-caught species) and the results regarding APT at different stages. Fish farming is expected to reduce the asymmetry phenomenon as compared to commercial fishing of wild species.

\section{THE MARKETING CHAINS OF COD AND SALMON}

The paper looks for possible APT of North Atlantic wild (whole fresh) cod (G. morhua) and farmed (whole fresh) Atlantic salmon ( $S$. salar) between the production and retailing sectors. The study is conducted between 1988 and 1999 when cod landings were still at meaningful levels compared to salmon imports and when products are homogenous throughout time. The study was extended to a more recent period (1998-2009) but with different results because products were too different along the period to allow for consistent samples (see footnote 6 and Tables A1 and A2 in the Appendix). Indeed, the two value chains have experienced important changes in the nature of the traded products (both species are increasingly sold as fillets or in pieces, including new processing and marketing costs within the chain ${ }^{1}$ ). During the last two decades, salmon has become a major species on the French market. Structural changes have led to a new role for intermediaries, shifting from mere commercial intermediation to sub-contracting (Guillotreau et al 2005). The two species accounted for a 30\% market share of total finfish in France (Tables 1 and 2). Cod has been consumed in France for centuries, the country traditionally being an important producing country until recently. However, as stocks of gadiforms ${ }^{2}$

\footnotetext{
${ }^{1}$ In Figures 1 and 2, prices for the two value chains are plotted along the full sample on a monthly basis (January 1988-April 2010) and show clearly the presence of structural breaks in the price series due to changing product forms over time.

${ }^{2}$ Group of species including the gadoid species (such as cod, haddock, etc.) and hake species. This group is also defined as the category of whitefish species.
} 
Table 2. Market shares in 1998

\begin{tabular}{llcr}
\hline & & Quantity & Value \\
\hline Whole fresh fish & Cod & $2.6 \%$ & $3.1 \%$ \\
& Salmon & $19.6 \%$ & $16.0 \%$ \\
Fresh steak and fillets & Cod & $15.0 \%$ & $14.7 \%$ \\
& Salmon & $19.4 \%$ & $21.0 \%$ \\
Total fresh products & Cod & $10.4 \%$ & $11.3 \%$ \\
& Salmon & $19.5 \%$ & $19.6 \%$ \\
\hline
\end{tabular}

Source: FranceAgrimer (http://www.franceagrimer.fr/).

became depleted in the North Atlantic, the domestic catches have decreased in proportion to a very low level. Cod is usually considered as the most representative and the most appreciated of the whitefish species with more than 100,000 mt consumed in 1998 under different product forms (frozen, fresh, breaded, fillets, etc.).

Approximately half of the fresh cod consumed in France comes from domestic landings, although the levels have sharply decreased since the early 1990s: stable around $50,000 \mathrm{mt}$, they dropped down to some 17,500 $\mathrm{mt}$ in 1998 and to only 4,800 $\mathrm{mt}$ in 2007 due to the reduction of the TAC and the national quota (share of the TAC). The product form (fresh, frozen, whole, or fillets) determines the market channel and the type of outlets. When the fish is domestically landed as whole fresh fish, the primary processors are the first buyers through an auction system, and they sell the fish (whole or filleted) either directly to the retailers and the restaurants, or to the middlemen on the wholesale markets located in the biggest French towns (Paris-Rungis, Bordeaux, Nantes, Marseille, etc.).

As with other food markets, the French market for cod has registered major structural changes over the past 20 years, such as the growing importance of supermarkets, the emerging consumption of processed food, and the globalization of supply, but it has been fairly stable in comparison with salmon consumption. The market share of salmon (in value) has sharply increased from less than $25 \%$ in 1976 to $40 \%$ in 1998 , despite a constant fall of salmon prices over the period and the increasing prices of whitefish species since 1995.

Atlantic salmon consumed in France is almost fully supplied by imports. In 1982, the market represented a quantity of about 23,000 metric tonnes $(\mathrm{t})$ and a value close to 1,500 millions of francs 1998 (230 million Euros). The North American producers (the United States and Canada) of wild-caught pacific salmon (Onchorynchus kisutch) supplied the most with two-thirds the supply. Sixteen years later, consumption has increased five fold to 112,000 $\mathrm{mt}$ (and even 150,000 $\mathrm{mt}$ in 2009) although the value has only been twofold in real terms (2,600 millions of francs 1998; 400 million Euros). Atlantic salmon ( $S$. salar) makes the bulk of the French market and is imported from European countries, in particular from Norway $(57,400 \mathrm{mt}$ in 1998 , including trade flows passing through Denmark) and Scotland $(22,600 \mathrm{mt})$.

The most recent data (2010) show that more than $70 \%$ of fresh salmon and cod are marketed by hyper- and supermarkets, far ahead of fishmongers, market stalls, and other retailers. "A more stable supply of fresh products, likely due to improvements in agricultural techniques and increased imports, contributes to a reduction in the variance 
of grower prices" (Worth 1999, p. 27). The increasing returns to scale and know-how of the Norwegian producers and the development of imports are two major features of the sector likely to fit with big multiple retailers because of the supply regularity and security they provide.

However, imports were subject to trade regulations during the period covered by the study. Beyond the customs tariff rates imposed under the Common Customs Tariff regime (autonomous rates of 16-20\%) and under the GATT/WTO (conventional rates of 2$15 \%$ ), safeguard mechanisms and antidumping measures were implemented to protect the European Union (EU) producers under the Common Organization of Markets (COM) framework (Le Grel et al 2003). One of the safeguard mechanisms provided under the $\mathrm{COM}$ is the provision for emergency measures. Under this provision, the commission may take unspecified measures if imports cause union markets to experience, or to be threatened with, "serious disturbances" which may endanger the objectives of the CFP. This provision has been used by the EU since 1991 to impose a minimum price for farmed Atlantic salmon imports from Norway. ${ }^{3}$

Empirical research is based on monthly prices for whole fresh fish between February 1988 and December 1999, using national sources for the data ${ }^{4}$ : all series are in French Francs per kg; Norwegian export prices were collected in Norwegian Kroners and converted with the Datastream exchange rate series.

The price series and the sample period have been selected in order to represent two short market channels, as far as possible without the intermediaries who may distort transmission. Therefore the difference in prices could be interpreted as gross marketing margins because there are low processing costs during that period of time, and transportation and labor costs are also fairly low. The main difference between the two marketing chains lies in the supply-side organization. More than $90 \%$ of fresh cod domestically produced is sold through auctions, unlike salmon purchased contractually for half of it by the multiple grocers to the Norwegian exporters, the other half being bought on the spot market (Guillotreau 2003). This split of the distribution of salmon reduces the spot market share and in an aggregated price series, diminishes the apparent variance in the price series.

\section{THRESHOLD COINTEGRATION}

Most of the studies dealing with APT of food markets use variants of an econometric technique introduced by Wolffram (1971), refined by Houck (1977), and generalized by Heien (1980) for estimating nonreversible functions. Another set of estimations based on

\footnotetext{
3 An MIP was introduced by the EU for the first time in November 1991 to all imports of Atlantic salmon. In 1994, this MIP only concerned the farmed Atlantic salmon. A floor price principle was adopted in 1995. In addition to these measures, two regulations enforcing fixed antidumping and countervailing duties were implemented in 1997. In 1999, last year of the period covered by the study, the former fixed duties became variable (for more details about this issue, see Le Grel et al 2003).

${ }^{4}$ Data sources: FranceAgrimer (http://www.franceagrimer.fr/) for the French landing price of whole fresh cod, the supermarket price of whole fresh cod and salmon; Norwegian Trade Statistics (http://www.ssb.no/fiskeri_havbruk_en/) for the Norwegian export price of whole fresh salmon. Nominal prices were considered because the study includes price series only.
} 
error-correction models (hereafter, ECM) fits better with nonstationary price series (von Cramon-Taubadel 1998). Finally, an innovative methodology has been introduced by Abdulai (2002) when he examines short- and long-run farm-retail price spread by using TAR and M-TAR models. Such cointegration models with asymmetric error correction were first developed by Enders and Granger (1998) in order to improve the traditional tests for unit roots and cointegration in the presence of asymmetric adjustment.

To obtain empirical evidence on the hypothesized difference between the two marketing channels, we implement the threshold cointegration models proposed by Enders and Siklos (2001) which is an extension of the two-step Engle and Granger (1987) procedure. Estimation proceeds as follows. The first step consists in estimating, via ordinary least squares, the long-run equilibrium relationship between the log-linearized price at the downstream level, denoted by $\ln P_{t}^{1}$, and the $\log$-linearized price at the upstream level, denoted by $\ln P_{t}^{2}$, for each fish species, that is

$$
\ln P_{t}^{1}=\alpha+\beta \ln P_{t}^{2}+\mu_{t}
$$

where $\alpha$ and $\beta$ denote parameters.

Equation (1) is identified with only prices at two different stages of the value chain, assuming that other marketing factors affecting the retail price are held constant. It seems to be a reasonable assumption to start with, in the case of fresh fish products. However, in the most recent period (1999-2010) whose results are not presented in this study, other inputs like the processing (filleting) costs should certainly be considered in the long-run relationship.

In a second step, relying on the estimated residuals $\mu^{\mathrm{EST}}{ }_{t}$, the equation

$$
\Delta \mu^{E S T}{ }_{t}=\rho_{1} M_{t} \mu^{E S T}{ }_{t-1}+\rho_{2}\left(1-M_{t}\right) \mu^{E S T}{ }_{t-1}+\sum_{j=1, \ldots, p} \gamma_{j} \Delta \mu^{E S T}{ }_{t-j}+\varepsilon_{t}
$$

is estimated using the indicator variable

$$
M_{t}=1, \text { if } \mu_{t-1}^{E S T} \geq \tau, \quad \text { and } \quad M_{t}=0, \text { if } \mu^{E S T}{ }_{t-1}<\tau
$$

where $\tau$ is the value of the threshold. Equations (1), (2), and (3a) represent a TAR model, where the indicator variable depends on the previous period value $\mu_{t-1}^{E S T}$. The adjustment is modeled by $\rho_{1} \mu^{E S T}{ }_{t-1}$, if $\mu^{E S T}{ }_{t-1}$ is above the threshold and by the term $\rho_{2} \mu_{t-1}^{E S T}$, if $\mu_{t-1}^{E S T}$ is below the threshold. Critical values for the $t$-statistics to test the null hypotheses $\rho_{1}=0$ and $\rho_{2}=0$ and for the $F$-statistics, denoted by $\Phi$, to test the null hypothesis $\rho_{1}=\rho_{2}=0$ can be found in Enders and Siklos (2001) (Tables 1 and 2 ). The rejection of the null hypothesis of no cointegration, that is, $\rho_{1}=\rho_{2}=0$, will indicate cointegration between the two price series. Moreover, if the null hypothesis of no cointegration is rejected, then the null hypothesis of symmetric adjustment, that is, $\rho_{1}=$ $\rho_{2}$, can be tested using the usual $F$-test.

Enders and Granger (1998) and Enders and Siklos (2001) suggest an alternative specification that can capture the "sharp" asymmetric movement in the series of the estimated residuals. In the introduction of this model, Enders and Granger (1998) describe it as better at capturing data that are characterized by "increases that tend to persist and 
Table 3. Results of the ADF and DF-GLS unit root tests (January 1988-December 1999)

\begin{tabular}{|c|c|c|c|c|c|}
\hline \multirow[b]{2}{*}{ Variable } & \multicolumn{3}{|c|}{$\mathrm{ADF}$ test } & \multicolumn{2}{|c|}{ DF-GLS test } \\
\hline & $\begin{array}{l}\text { No constant, } \\
\text { no trend }\end{array}$ & $\begin{array}{l}\text { Constant, } \\
\text { no trend }\end{array}$ & $\begin{array}{l}\text { Constant } \\
\text { and trend }\end{array}$ & $\begin{array}{l}\text { Constant, } \\
\text { no trend }\end{array}$ & $\begin{array}{l}\text { Constant } \\
\text { and trend }\end{array}$ \\
\hline $\begin{array}{l}\text { French retail price of } \\
\text { fresh cod }\end{array}$ & $\begin{array}{c}0.541 \\
(\operatorname{lags}=8)\end{array}$ & $\begin{array}{c}-2.282 \\
(\operatorname{lags}=4)\end{array}$ & $\begin{array}{c}-2.335 \\
(\operatorname{lags}=8)\end{array}$ & $\begin{array}{c}-0.591 \\
(\operatorname{lags}=8)\end{array}$ & $\begin{array}{c}-1.420 \\
(\operatorname{lags}=8)\end{array}$ \\
\hline $\begin{array}{l}\text { French landing price } \\
\text { of fresh cod }\end{array}$ & $\begin{array}{c}0.680 \\
(\operatorname{lags}=13)\end{array}$ & $\begin{array}{c}-1.691 \\
(\operatorname{lags}=13)\end{array}$ & $\begin{array}{c}-1.751 \\
(\operatorname{lags}=13)\end{array}$ & $\begin{array}{c}-1.600 \\
(\operatorname{lags}=13)\end{array}$ & $\begin{array}{c}-1.886 \\
(\operatorname{lags}=13)\end{array}$ \\
\hline $\begin{array}{l}\text { French retail price of } \\
\text { fresh salmon }\end{array}$ & $\begin{array}{l}-2.010^{* *} \\
(\operatorname{lags}=12)\end{array}$ & $\begin{array}{c}-2.424 \\
(\operatorname{lags}=12)\end{array}$ & $\begin{array}{c}-3.558^{* *} \\
(\operatorname{lags}=12)\end{array}$ & $\begin{array}{c}0.886 \\
(\operatorname{lags}=12)\end{array}$ & $\begin{array}{c}-1.114 \\
(\operatorname{lags}=12)\end{array}$ \\
\hline $\begin{array}{l}\text { Price of fresh salmon } \\
\text { imported from } \\
\text { Norway }\end{array}$ & $\begin{array}{l}-2.094^{* *} \\
(\operatorname{lags}=6)\end{array}$ & $\begin{array}{c}-2.281 \\
(\operatorname{lags}=6)\end{array}$ & $\begin{array}{c}-1.803 \\
(\operatorname{lags}=6)\end{array}$ & $\begin{array}{c}0.393 \\
(\operatorname{lags}=6)\end{array}$ & $\begin{array}{c}-1.432 \\
(\operatorname{lags}=6)\end{array}$ \\
\hline
\end{tabular}

Notes: Series are expressed in logarithm.

Statistical significance is indicated by a single asterisk $\left({ }^{*}\right)$ for the $10 \%$ level and a double asterisk $(* *)$ for the $5 \%$ level.

decreases that tend to revert quickly to the attractor," for example. Thus, they set the indicator function as the following

$$
M_{t}=1, \text { if } \Delta \mu_{t-1}^{E S T} \geq \tau, \quad \text { and } \quad M_{t}=0, \quad \text { if } \Delta \mu_{t-1}^{E S T}<\tau
$$

Equations (1), (2), and (3b) represent an M-TAR model where the indicator variable depends now on the previous period change $\Delta \mu_{t-1}^{E S T}$. The adjustment is modeled by $\rho_{1} \mu^{E S T}{ }_{t-1}$, if $\Delta \mu^{E S T}{ }_{t-1}$ is above the threshold $\tau$, and by the term $\rho_{2} \mu^{E S T}{ }_{t-1}$, if $\Delta \mu^{E S T}{ }_{t-1}$ is below the threshold $\tau$. The null hypothesis of no cointegration, that is, $\rho_{1}=$ $\rho_{2}=0$, can then be tested using the $F$-statistics, also denoted by $\Phi$, whose critical values have been tabulated by Enders and Siklos (2001). Moreover, if the null hypothesis of no cointegration is rejected, then the null hypothesis of symmetric adjustment, that is, $\rho_{1}=$ $\rho_{2}$, can be tested using the usual $F$-test.

The first point to note is that the two previous models assume that the value of the threshold parameter $\tau$ is known. Thus, they reduce to the models studied by Enders and Granger (1998) when $\tau=0$. To estimate consistently this threshold parameter, we use Chan's method (1993). This method involves sorting the estimated residuals $\mu_{t}{ }^{E S T}{ }_{t}$ in ascending order, excluding the 15\% largest and smallest values and selecting from the remaining $70 \%$ values the threshold which yields the lowest residual sum of squares when estimating an equation in the form of Equation (2) with an indicator function defined by Equation (3a). For an M-TAR model (the indicator function is now defined by Equation [3b]), the method involves now sorting the estimated change $\Delta \mu_{t}{ }^{E S T}{ }_{t}$ in ascending order, and so on. Chan (1993) showed that searching over the potential threshold values so as to minimize the residual sum of squares yields a (super)consistent estimate of the threshold in that it converges in distribution with a speed of convergence proportional to the sample size T. Moreover, asymptotic inference about the TAR parameters $\rho_{1}$ and $\rho_{2}$ can proceed as if the threshold value was known. Given this estimated threshold value, 


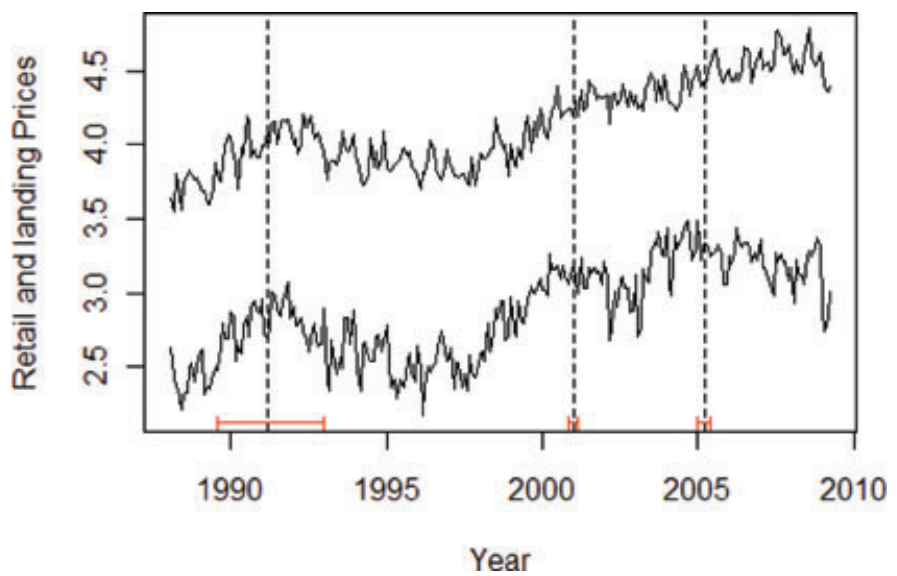

Source: FranceAgrimer (http://www.franceagrimer.fr/).

Figure 1. Landing and supermarket fresh cod prices in France (series are in logarithm of French Francs per kilogram; $1 €=6.55957 \mathrm{FF}$ )

cointegration and symmetry tests can then be implemented using the tests presented above.

\section{EMPIRICAL RESULTS}

Unit root tests, standard cointegration tests, and asymmetric TAR and M-TAR models which are consistent $(\tau \neq 0)$ or not $(\tau=0)$, are implemented for the logarithm of the retail price and the logarithm of the shipping price of cod and salmon. In France, retail and ex-vessel prices of whole fresh salmon and whole fresh cod have been collected from the National office of agricultural and seafood products (France Agrimer), respectively, through a large panel of consumers (Kantar Worldpanel) and from a comprehensive set of 40 auction markets of fishery products (Réseau Inter-Criées-RIC). Salmon export prices were collected from the Norwegian Bureau of Statistics on the basis of national customs (unit values of whole fresh salmon). Regarding possible errors in variables, one could consider measurement errors in the retail prices due to the sampling procedure adopted but not in the independent variables coming from comprehensive surveys. Their time paths are reported in Figures 1 and 2.

\section{Stochastic Properties of the Series}

First, we investigate the stochastic properties of the four price series individually implementing the test approaches proposed by Dickey and Fuller $(1979,1981)$. The lag length $p$ of the ADF regression is determined using the Hall's (1994) general-to-specific procedure where the upper bound $p_{\max }$ is given by Schwert's (1989) formula: $p_{\max }=$ integer part of $12(T / 100)^{1 / 4}$. Results of the ADF tests are reported in Table 2. These tests clearly indicate that the null hypothesis of a unit root cannot be rejected when considering the French retail price of fresh cod, the French landing price of the fresh cod, and the price of fresh salmon imported from Norway. The results are less clear-cut when considering the French retail price of fresh salmon. But it is well known that in testing for unit root 


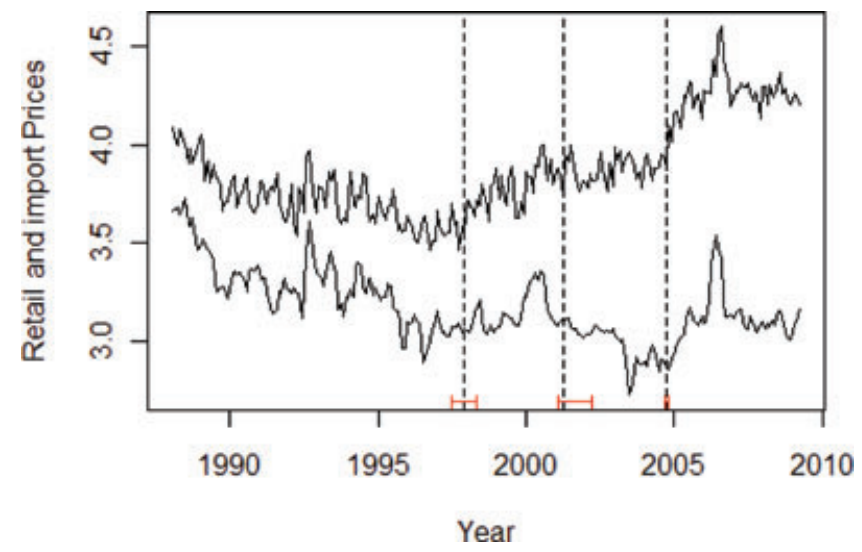

Sources: FranceAgrimer (http://www.franceagrimer.fr/); Norwegian Trade Statistics (http://www.ssb.no/fiskeri_havbruk_en/).

Figure 2. Import and supermarket prices of fresh salmon in France (series are in logarithm of French Francs per kilogram; $1 €=6.55957$ FF)

nonstationarity, the power of the ADF test is questionable. To minimize this problem, a modified Dickey-Fuller test with good properties is also applied, in addition to the usual augmented Dickey-Fuller (ADF) test.

In order to improve the power of the unit root test, Elliott et al (1996) proposed a local to unity de-trending of the time series. They then developed feasible point-optimal tests that take serial correlation of the error term into account. In particular, they suggest the Dickey-Fuller GLS (hereafter, DF-GLS) which is a modified ADF test applied to the de-trended data without the intercept. Let $P_{t}$ be the considered price series. The DF-GLS $t$-test is performed by testing the null hypothesis $\theta_{0}=0$ in the regression.

$$
\Delta P^{d}{ }_{t}=\theta_{0} P^{d}{ }_{t-1}+\sum_{j=1, \ldots, p} \theta_{j} \Delta P^{d}{ }_{t-j}+\varepsilon_{t}
$$

where $\varepsilon_{t}$ is the random error term, and $P_{t}^{d}$ is the locally de-trended price series. The local de-trending depends on whether we consider a model with drift only or a linear trend, that is, the local de-trended price series is defined as $P^{d}{ }_{t}=P_{t}-\beta Z_{t}$, with $Z_{t}=1$ in the first case, and $Z_{t}=(1, t)$ in the second case. The parameters $\beta$ are obtained by regressing $P^{\text {trans }}$ on $Z^{\text {trans }}$ where $P^{\text {trans }}=\left(P_{1}, P_{2}-\lambda P_{1}, \ldots, P_{T}-\lambda P_{T-1}\right)^{\prime}, Z^{\text {trans }}=\left(Z_{1}, Z_{2}-\lambda Z_{1}, \ldots, Z_{T-}\right.$ $\left.\lambda Z_{T-1}\right)^{\prime}$. The scalar $\lambda$ is set to $\lambda=1+c / T$ where $c$ denotes a constant. Depending on the deterministic component in $Z_{t}, c$ is set either to -7 in the case of a constant or to -13.5 in the case of a linear trend. These values have been derived from the asymptotic power functions and its envelope. Critical values for the DF-GLS test are provided in Elliott et al (1996).

The results of the DF-GLS tests are also reported in Table 3. The lag length for each test is chosen using Hall's (1994) general-to-specific procedure. The results clearly show that the null hypothesis of a unit root cannot be rejected whatever the considered price series. 


\section{Cointegration and Asymmetric Estimations}

Following the cointegration analysis in the Engle and Granger (1987) sense, the long-run equilibrium relationships between upstream prices and downstream prices are estimated by ordinary least squares. The estimated long-run equilibrium relationships are:

Codfish:

$$
\ln P^{1}=2.847+0.398 \ln P_{t}^{2}+\mu^{E S T}{ }_{t}
$$

Salmon ${ }^{5}$

$$
\ln P^{1}=1.912+0.535 \ln P_{t}^{2}+\mu^{E S T}{ }_{t}
$$

where $\ln P^{1}{ }_{t}$ denotes the $\log$-linearized price at the downstream level and $\ln P^{2}{ }_{t}$, the $\log$ linearized price at the upstream level. Thus, the parameters of $\ln P^{2}{ }_{t}$ can be interpreted as the long-run elasticities of the price $P^{1}$ with respect to the price $P^{2}$. They give in fact the magnitude of adjustment of the retail price to the variations of the shipping price. Their estimated values indicate that shifts in the shipping price are not fully passed onto retail price. Moreover, the magnitude is higher for salmon than for codfish.

Next, following the Engle-Granger methodology, the residuals of each equation are used to estimate

$$
\Delta \mu^{E S T}{ }_{t}=\rho_{1} \mu^{E S T}{ }_{t-1}+\sum_{j=1, \ldots, p} \gamma_{j} \Delta \mu^{E S T}{ }_{t-j}+\varepsilon_{t}
$$

Akaike and Schwarz information criterions (AIC and SIC, respectively) are used in order to choose the number of lags $p$ in this equation. As shown in Tables 4 and 5, the model using no lagged change seems to be appropriate in the case of codfish while a model using one-lagged change seems to be more appropriate in the case of salmon. As reported in the second column of these tables, the $t$-statistics for the null hypothesis that $\rho_{1}=0$ are quite large. At the conventional significance levels, the Engle-Granger test clearly indicates that the two price series are cointegrated whatever the considered fish species.

Next, we estimated the residuals of each Equation (4a) or (4b) in the form of a TAR model or an M-TAR model using the threshold $\tau=0$. The third and fourth columns of Tables 4 and 5 report the corresponding results. The point estimates for $\rho_{1}$ and $\rho_{2}$ clearly indicate convergence. Indeed, these values are all negative and satisfy $\left(1+\rho_{1}\right)$ $\left(1+\rho_{2}\right)<1$. All the associated $t$-statistics are less than the $1 \%$ critical value for the $t$-max statistics, that is, approximately -2.57 . Moreover, all the sample values of the $\Phi$-statistics

\footnotetext{
5 Tested on a more recent sample period (January 1998 to April 2009), the long-run equilibrium relationship was the following one for fresh salmon (it was not possible to find any consistent relationship for cod prices): $\ln P^{1}{ }_{t}=2.985+0.377 \ln P^{2}{ }_{t}+\mu^{E S T}{ }_{t}$ (4c) $[t$-stat are 12.058 and 4.702, respectively]. But evidence of a cointegration relationship is weak, and the APT tests on TAR and M-TAR models gave odd results (see Tables A1 and A2 in the Appendix), presumably because of this lack of long-run relationship.
} 
Table 4. Estimates of price transmission in the codfish value chain (January 1988-December 1999)

\begin{tabular}{lccccc}
\hline & $\begin{array}{c}\text { Engle- } \\
\text { Granger }\end{array}$ & Threshold & Momentum & $\begin{array}{c}\text { Threshold- } \\
\text { consistent }\end{array}$ & $\begin{array}{c}\text { Momentum- } \\
\text { consistent }\end{array}$ \\
\hline$\rho_{1}$ & -0.630 & -0.500 & -0.551 & -0.456 & -0.512 \\
& $(-8.161)^{1}$ & $(-4.255)$ & $(-6.943)$ & $(-4.183)$ & $(-5.301)$ \\
$\rho_{2}$ & NA & -0.727 & -0.730 & -0.796 & -0.882 \\
& & $(-7.153)^{2}$ & $(-4.750)$ & $(-7.481)$ & $(-6.984)$ \\
$\tau$ & NA & 0 & 0 & -0.112 & -0.107 \\
$\mathrm{AIC}^{3}$ & -1.364 & -1.365 & -1.367 & -1.385 & -1.396 \\
$\mathrm{SIC}^{3}$ & -1.323 & -1.325 & -1.325 & -1.343 & -1.354 \\
$\Phi^{4,5}$ & $\mathrm{NA}$ & 34.637 & 35.380 & 36.729 & 38.441 \\
$\rho_{1}=\rho_{2}{ }^{6}$ & $\mathrm{NA}$ & 2.135 & 1.302 & 4.977 & 5.397 \\
& & $(0.146)$ & $(0.256)$ & $(0.027)$ & $(0.022)$ \\
\hline
\end{tabular}

Notes: ${ }^{1}$ Entries in this row are the $t$-statistics for the null hypothesis $\rho_{1}=0$.

${ }^{2}$ Entries in this row are the $t$-statistics for the null hypothesis $\rho_{2}=0$.

${ }^{3} \mathrm{AIC}$ and SIC denote the Akaike and the Schwarz criterions. The AIC and SIC are computed as: $-2 L / T+2 K / T$, and $-2 L / T+K \log (T) / T$, respectively, where $L$ denotes the likelihood and $K$ is the number of regressors in the estimated model.

${ }^{4}$ Entries in this row and in the third and fourth columns are the sample values of the TAR and M-TAR $\Phi$-statistics. Critical values for TAR $\Phi$ for a two variable case and no lagged change are approximatively $5.01,5.98$, and 8.24 for $10 \%, 5 \%$, and $1 \%$ respectively. The corresponding values for M-TAR $\Phi$ are approximatively 5.45, 6.51, and 8.78. See table 1 in Enders and Siklos (2001).

${ }^{5}$ Entries in this row and in the fifth and sixth columns are the sample values of the TAR-consistent and M-TAR-consistent $\Phi$-statistics. Critical values for TAR-consistent $\Phi$ for a two variable case and no lagged change are approximately 5.95, 6.95, and 9.27 for $10 \%, 5 \%$, and $1 \%$, respectively. The corresponding values for M-TAR $\Phi$ are approximately 5.73, 6.78, and 9.14. See table 5 in Enders and Siklos (2001).

${ }^{6}$ Entries in this row are the sample $F$-statistics for the null hypothesis that the adjustment coefficients are equal. Significance levels are in parentheses below.

largely exceed the $1 \%$ critical value (approximately 8.30 ). The null hypothesis $\rho_{1}=\rho_{2}=0$ can therefore be rejected, confirming that the price series are co-integrated regardless of the fish species considered. Given the price series are co-integrated, the null hypothesis of symmetric adjustment (i.e., $\rho_{1}=\rho_{2}$ ) can be tested using a standard $F$-distribution (Enders and Granger 1998). All the sample $F$-statistics values and their associated $p$-values clearly indicate that this null hypothesis cannot be rejected at usual levels of significance whatever the considered TAR or M-TAR model or fish species. Thus using the standard Enders and Granger's (1998) methodology, that is, assuming that $\tau=0$, price transmission seems to be symmetric in the two value chains.

Next we use Chan's (1993) method to find the consistent estimates of the thresholds. When we searched over the possible thresholds lying in the middle $70 \%$ of the sorted values of $\left\{\mu^{E S T}{ }_{t}\right\}$ in the case of the codfish species, we found that a threshold of -0.112 results in the smallest residual sum of squares. The results of the estimation of the corresponding TAR model are reported in the fifth column of Table 4 . When we performed the same 
Table 5. Estimates of price transmission in the salmon value chain (January 1988-December 1999)

\begin{tabular}{lccccc}
\hline & $\begin{array}{c}\text { Engle- } \\
\text { Granger }\end{array}$ & Threshold & Momentum & $\begin{array}{c}\text { Threshold- } \\
\text { consistent }\end{array}$ & $\begin{array}{c}\text { Momentum- } \\
\text { consistent }\end{array}$ \\
\hline$\rho_{1}$ & -0.739 & -0.759 & -0.718 & -0.868 & -0.651 \\
& $(-7.860)^{1}$ & $(-6.096)$ & $(-5.989)$ & $(-7.975)$ & $(-5.999)$ \\
$\rho_{2}$ & NA & -0.719 & -0.762 & -0.488 & -0.908 \\
& & $(-5.953)^{2}$ & $(-6.062)$ & $(-3.388)$ & $(-6.416)$ \\
$\gamma_{1}$ & 0.175 & 0.176 & 0.175 & 0.195 & 0.191 \\
& $(2.101)^{3}$ & $(2.097)$ & $(2.096)$ & $(2.356)$ & $(2.283)$ \\
$\tau$ & NA & 0 & 0 & -0.099 & -0.035 \\
AIC $^{4}$ & -2.447 & -2.434 & -2.432 & -2.470 & -2.452 \\
SIC $^{4}$ & -2.406 & -2.371 & -2.371 & -2.407 & -2.389 \\
$\Phi^{5,6}$ & NA & 30.716 & 30.723 & 34.367 & 32.509 \\
$\rho_{1}=\rho_{2}{ }^{7}$ & NA & 0.066 & 0.077 & 5.122 & 2.550 \\
& & $(0.798)$ & $(0.783)$ & $(0.025)$ & $(0.112)$ \\
\hline
\end{tabular}

Notes: ${ }^{1}$ Entries in this row are the $t$-statistics for the null hypothesis $\rho_{1}=0$.

${ }^{2}$ Entries in this row are the $t$-statistics for the null hypothesis $\rho_{2}=0$.

${ }^{3}$ Entries in this row are the $t$-statistics for the null hypothesis $\gamma_{1}=0$.

${ }^{4} \mathrm{AIC}$ and SIC denote the Akaike and the Schwarz criterions. The AIC and SIC are computed as: $-2 L / T+2 K / T$, and $-2 L / T+K \log (T) / T$, respectively, where $L$ denotes the likelihood and $K$ the number of regressors in the estimated model.

${ }^{5}$ Entries in this row and in the third and fourth columns are the sample values of the TAR and M-TAR $\Phi$-statistics. Critical values for TAR $\Phi$ for a two variable case and one lagged change are approximatively $4.99,6.01$, and 8.30 for $10 \%, 5 \%$, and $1 \%$ respectively. The corresponding values for M-TAR $\Phi$ are approximatively 5.47, 6.51, and 8.65. See table 1 in Enders and Siklos (2001).

${ }^{6}$ Entries in this row and in the fifth and sixth columns are the sample values of the TAR-consistent and M-TAR-consistent $\Phi$-statistics. Critical values for TAR-consistent $\Phi$ for a two variable case and one lagged change are approximatively $6.02,7.08$, and 9.51 for $10 \%, 5 \%$, and $1 \%$, respectively. The corresponding values for M-TAR-consistent $\Phi$ are approximatively 5.76, 6.86, and 9.29. See table 6 in Enders and Siklos (2001).

${ }^{7}$ Entries in this row are the sample $F$-statistics for the null hypothesis that the adjustment coefficient is equal. Significance levels are in parentheses below.

search using the M-TAR model so that the potential thresholds are now the middle $70 \%$ of the sorted values of $\left\{\Delta \mu^{E S T}{ }_{t}\right\}$, we found a threshold of -0.107 (see the sixth column of Table 4). In the case of the salmon species, the consistent estimates of the thresholds we obtained using similar search procedures, are -0.099 and -0.035 for the TAR and M-TAR models. The first point to note is that all the point estimates of $\rho_{1}$ and $\rho_{2}$ are significantly different of zero, and that all the $\Phi$-statistics clearly indicate the rejection of the null hypothesis $\rho_{1}=\rho_{2}=0$ at the usual levels of significance, whatever the considered model and fish species. The upstream and downstream price series are thus co-integrated, whatever the considered fish species. The second point to note is that the $F$-test for symmetric adjustment can be rejected at the $5 \%$ level when considering the codfish species, whatever the considered model, while it can be rejected at the same level 
only when considering the TAR-consistent model in the case of the salmon species. These findings suggest that the adjustment is asymmetric in the two value chains.

Both the TAR-consistent and the M-TAR-consistent models suggest asymmetric adjustment for the series in the codfish case while only the TAR-consistent model in the salmon case. Thus, it would be interesting to ascertain whether adjustment follows a TAR or an M-TAR process. For such a test, Enders and Granger (1998) suggest using the values of the usual information criterions, AIC and BIC, to select the model with the best overall fit. As is evident in fifth and sixth columns of Table 4 (respectively, Table 5), the M-TAR-consistent model (respectively, TAR-consistent model) yields the lowest AIC and SIC and is therefore preferable for explaining asymmetric adjustment in the cod (respectively, salmon) value chain.

To sum up, the estimates suggest asymmetric adjustment in the two value chains but the way this asymmetric adjustment occurs differs between the two value chains. In the codfish value chain, the adjustment process can be represented by the following M-TAR-consistent model

$$
\Delta \mu_{t}^{E S T}=-0.512 M_{t} \mu_{t-1}^{E S T}-0.882\left(1-M_{t}\right) \mu_{t-1}^{E S T}+\varepsilon_{t}
$$

where $M_{t}=1$ when $\Delta \mu_{t-1}^{E S T} \geq-0.107$ and $M_{t}=0$ when $\Delta \mu_{t-1}^{E S T}<-0.107$, while in the salmon value chain, the adjustment process can be represented by a TAR-consistent model of the form

$$
\Delta \mu_{t}^{E S T}=-0.868 M_{t} \mu_{t-1}^{E S T}-0.488\left(1-M_{t}\right) \mu_{t-1}^{E S T}+0.195 \Delta \mu_{t}^{E S T}+\varepsilon_{t}
$$

where $M_{t}=1$ when $\mu_{t-1}^{E S T} \geq-0.099$ and $M_{t}=0$ when $\mu_{t-1}^{E S T}<-0.099$.

\section{Short-Run Dynamics}

The finding of co-integration with asymmetric adjustment given by M-TAR model in the case of the codfish value chain or a TAR model in the case of the salmon value chain represents the short-run dynamics of the log-linearized price at the downstream level as an ECM like

$$
\Delta \ln P^{1}{ }_{t}=\gamma_{1} E C T^{+}{ }_{t-1}+\gamma_{2} E C T^{-}{ }_{t-1}+\sum_{j=1^{P}} \delta^{1}{ }_{j} \Delta \ln P_{t-j}^{1}+\sum_{j=0^{P}} \delta^{2}{ }_{j} \Delta \ln P^{2}{ }_{t-j}+\varepsilon_{t}
$$

where $p$ is lag-length, and the error-correction terms $E C T^{+}{ }_{t-1}$ and $E C T^{-}{ }_{t-1}$ are defined as

$$
\begin{aligned}
& E C T^{+}{ }_{t-1}=I\left(\Delta \mu^{E S T}{ }_{t-1} \geq-0.107\right)\left(\ln P^{1}{ }_{t-1}-2.847-0.398 \ln P^{2}{ }_{t-j}\right) \text { and } \\
& E C T^{-}{ }_{t-1}=\mid\left(\Delta \mu^{E S T}{ }_{t-1}<-0.107\right)\left(\ln P^{1}{ }_{t-1}-2.847-0.398 \ln P^{2}{ }_{t-j}\right)
\end{aligned}
$$

when considering the codfish value chain, or

$$
\begin{aligned}
& E C T^{+}{ }_{t-1}=\mathrm{I}\left(\mu^{E S T}{ }_{t-1} \geq-0.099\right)\left(\ln P^{1}{ }_{t-1}-1.912-0.535 \ln P^{2}{ }_{t-j}\right) \text { and } \\
& E C T^{-}{ }_{t-1}=\mathrm{I}\left(\mu^{E S T}{ }_{t-1}<-0.099\right)\left(\ln P^{1}{ }_{t-1}-1.912-0.535 \ln P_{t-j}^{2}\right)
\end{aligned}
$$

when considering the salmon value chain. 
As emphasized by von Cramon-Taubadel (1998), a valid statistical analysis of the dynamics of the downstream price series requires $\ln P^{2}{ }_{t}$ to be weakly exogenous with respect of the parameter of interest Equation (7). Testing the weak exogeneity of this variable can be carried out by examining whether the $E C T^{+}{ }_{t-1}$ and $E C T^{-}{ }_{t-1}$ are not statistically significant when considering the marginal model (Boswijk and Urbain 1997)

$$
\Delta \ln P^{2}{ }_{t}=\varphi_{1} E C T^{+}{ }_{t-1}+\varphi_{2} E C T^{-}{ }_{t-1}+\sum_{j=1}{ }^{\mathrm{P}} \phi^{1}{ }_{j} \Delta \ln P_{t-j}^{1}+\sum_{j=1}{ }^{\mathrm{P}} \phi_{j}^{2} \Delta \ln P^{2}{ }_{t-j}+\varepsilon_{\mathrm{t}}
$$

Estimates of the conditional ECM (Equation [7]) and of the marginal ECM (Equation [8]) for each value chain are reported in Table 6 (the SIC is used to determine the lag-length). Before proceeding with the weak exogeneity tests, it is imperative to check each estimated ECM for possible misspecification. Results from various diagnostic tests (Ljung-Box $Q$-statistics with four lags, ARCH-LM test, and Breusch-Godfrey serial correlation test) confirm the absence of any serious misspecification in the estimated ECM. We turn now to the results of the weak exogeneity test. The $F$-statistic for the null hypothesis $\varphi_{1}=\varphi_{2}=0$ is 1.732 when considering the price series in the codfish value chain, and 1.274 when considering the salmon value chain. Their respective empirical significance level, that is, $18.09 \%$ and $28.31 \%$, do not allow rejecting the considered null hypothesis. Upstream prices are weakly exogenous whatever the value chain.

The estimates of the asymmetric ECMs presented in Table 6 are now used to develop impulse response functions to further examine the dynamic interrelationships among the upstream and downstream prices in the two value chains. Figures $3 \mathrm{a}$ and $\mathrm{b}$ illustrates responses of the log-run equilibrium margin to $1 \%, 5 \%, 10 \%$, and $20 \%$ positive or negative variations in the logarithm of the upstream price for the two value chains. As expected, responses to small upstream price variations are symmetric. Asymmetries occur when considering large price variations. While the margin returns to its long-run equilibrium value within the same period whatever the variation being positive or negative, the responses are contrasted. Thus, the downstream price adjusts more quickly to an increase in the upstream price when considering the codfish value chain while the opposite result is observed with the salmon value chain.

\section{DISCUSSION}

For both fish species (cod and salmon) price series at two different stages of the marketing chain were found co-integrated during the period 1988-99. Price causation proved to be unidirectional in all cases, going downward from the ex-vessel or ex-farm price to the retail price (ECM testing the hypothesis of weak exogeneity). Consequently, production prices and retail prices are moving altogether in the long run, retailers adjusting their prices to the price changes upstream.

As far as APT tests were concerned, price transmission was found symmetrical for both species in a first step (with a zero threshold), but a threshold different from zero rejected the symmetry test for the two species.

The identification of a nonzero threshold is justified since no empirical or theoretical background supports $a$ priori the use of a zero threshold in the analysis of APT. Indeed, one could admit that a price adjustment down the chain is triggered by either a contractual agreement between the supplier and the buyer, or by an excessive contraction of the 

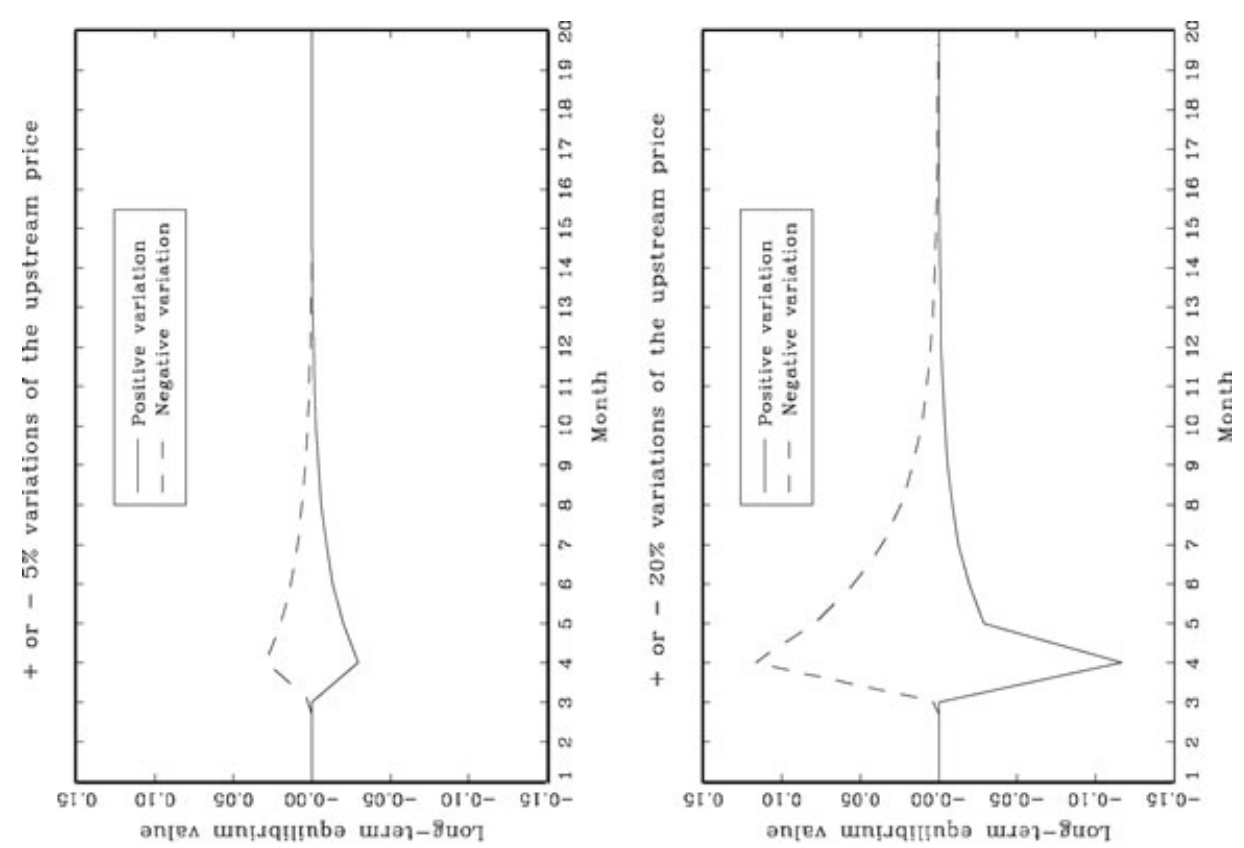

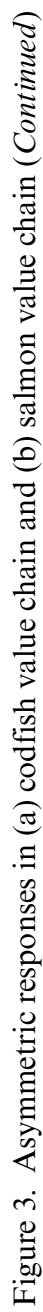
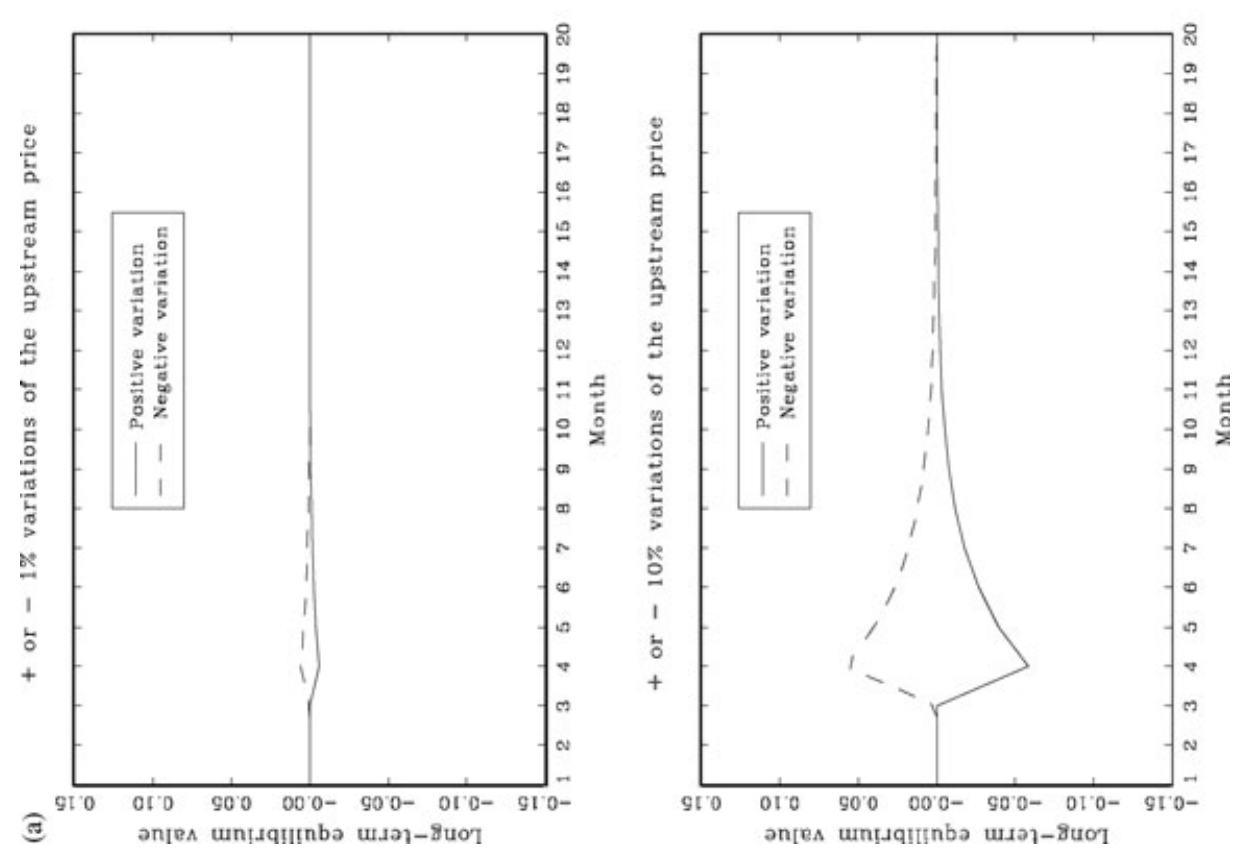

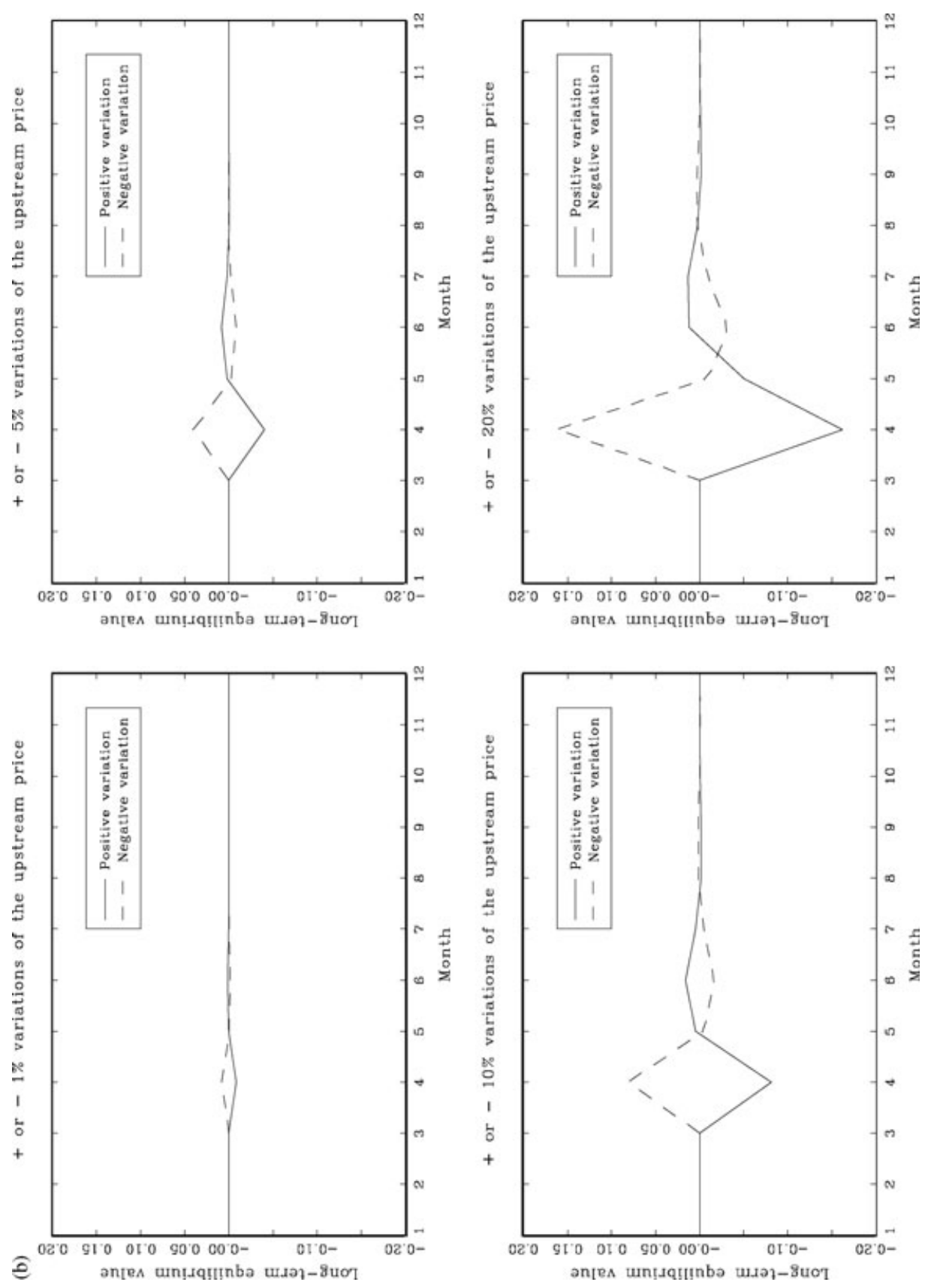

ن 
Table 6. Estimates of the error correction models (January 1988-December 1999)

\begin{tabular}{|c|c|c|c|c|}
\hline & \multicolumn{2}{|c|}{ Codfish } & \multicolumn{2}{|c|}{ Salmon } \\
\hline & $\Delta P_{t}^{1}$ & $\Delta P_{t}^{2}$ & $\Delta P^{1}{ }_{t}$ & $\Delta P_{t}^{2}$ \\
\hline$E C T^{+}{ }_{t-1}$ & $\begin{array}{c}-0.326 \\
(-2.861)\end{array}$ & $\begin{array}{c}0.199 \\
(1.711)\end{array}$ & $\begin{array}{c}-0.843 \\
(-8.280)\end{array}$ & $\begin{array}{c}0.116 \\
(1.435)\end{array}$ \\
\hline$E C T^{-}{ }_{t-1}$ & $\begin{array}{c}-0.753 \\
(-5.171)\end{array}$ & $\begin{array}{c}-0.059 \\
(-0.412)\end{array}$ & $\begin{array}{c}-0.469 \\
(-2.908)\end{array}$ & $\begin{array}{c}0.068 \\
(1.118)\end{array}$ \\
\hline$\Delta P_{t-1}^{1}$ & $\begin{array}{l}-0.155 \\
(-1.293)\end{array}$ & $\begin{array}{c}0.065 \\
(0.685)\end{array}$ & $\begin{array}{c}0.181 \\
(2.520)\end{array}$ & $\begin{array}{c}-0.030 \\
(-0.432)\end{array}$ \\
\hline$\Delta P_{t-2}^{1}$ & $\begin{array}{l}-0.113 \\
(-1.115)\end{array}$ & $\begin{array}{c}0.111 \\
(1.369)\end{array}$ & NA & NA \\
\hline$\Delta P^{2}{ }_{t}$ & $\begin{array}{c}0.178 \\
(2.466)\end{array}$ & NA & $\begin{array}{c}0.292 \\
(2.300)\end{array}$ & NA \\
\hline$\Delta P^{2}{ }_{t-1}$ & $\begin{array}{c}0.027 \\
(0.296)\end{array}$ & $\begin{array}{c}-0.345 \\
(-4.363)\end{array}$ & $\begin{array}{c}-0.091 \\
(-0.847)\end{array}$ & $\begin{array}{c}0.281 \\
(2.456)\end{array}$ \\
\hline$\Delta P_{t-2}^{2}$ & $\begin{array}{c}-0.031 \\
(-0.479)\end{array}$ & $\begin{array}{c}-0.408 \\
(-5.572)\end{array}$ & NA & NA \\
\hline$R^{2}$ & 0.364 & 0.255 & 0.359 & 0.072 \\
\hline DW & 1.948 & 2.053 & 2.023 & 1.896 \\
\hline Ljung-Box $Q$-statistics with four lags & $\begin{array}{c}3.117 \\
(0.538)\end{array}$ & $\begin{array}{c}0.653 \\
(0.957)\end{array}$ & $\begin{array}{c}3.960 \\
(0.411)\end{array}$ & $\begin{array}{c}4.510 \\
(0.291)\end{array}$ \\
\hline ARCH-LM test & $\begin{array}{c}1.010 \\
(0.315)\end{array}$ & $\begin{array}{c}0.356 \\
(0.550)\end{array}$ & $\begin{array}{c}0.286 \\
(0.594)\end{array}$ & $\begin{array}{c}4.510 \\
(0.035)\end{array}$ \\
\hline Breusch-Godfrey serial correlation test & $\begin{array}{c}0.695 \\
(0.706)\end{array}$ & $\begin{array}{c}0.893 \\
(0.640)\end{array}$ & $\begin{array}{c}1.377 \\
(0.502)\end{array}$ & $\begin{array}{c}3.557 \\
(0.169)\end{array}$ \\
\hline
\end{tabular}

Notes: Numbers in parentheses under the estimated values of the coefficients are White's heteroskedastic-consistent $t$-values.

Numbers in parentheses under the test statistics are their empirical significance level.

marketing margin beyond a certain level. As long as long term contracts which include pricing conditions are poorly represented in the salmon international trade (Guillotreau 2003, p. 189), the second explanation is preferred. The negative threshold means that a new behavior takes place after a substantial reduction of the margin. A positive threshold would be presumably more questionable and difficult to interpret, since there is no obvious incentive for the retailer to give up higher temporary unit margins. The negative threshold can be interpreted as follows: below a certain reduction of margin, variations of the upstream price are symmetrically transmitted by the retailer to the consumer as a routine, considering this reduction as bearable or temporary. Beyond this value, the reduction of the margin represents a threat to the profitability of the intermediaries who then adopt a different strategy.

Our empirical results give a strong support to this conclusion since the threshold (around $-10 \%$ ) is similar for both products marketed through the same channel of supermarkets, as though the latter would follow the same pricing strategy whatever the fish species. Indeed the threshold is unique and negative and can be interpreted as follows: 
Table 7. Summary of the asymmetry results (January 1988-December 1999)

\begin{tabular}{lccc}
\hline Species & Model & $\rho_{1}$ & $\rho_{2}$ \\
\hline Cod (wild) & $\begin{array}{c}\text { M-TAR consistent } \\
\text { (threshold }=-0.107) \\
\text { TAR consistent } \\
\text { Salmon (farmed) }\end{array}$ & -0.512 & -0.882 \\
& (threshold $=-0.099)$ & -0.868 & -0.488 \\
\hline
\end{tabular}

whenever the margin increases or decreases by less than $10 \%$, the upstream price variation is transmitted on a symmetric basis. Whenever the margin decreases by more than $10 \%$, asymmetry occurs.

Interestingly, the asymmetry goes in opposite ways for farmed salmon on the one hand and the wild-harvested cod on the other: price decreases upstream are more rapidly transmitted at the retail stage in the former case, whereas increases of the ex-vessel price are more quickly passed onto the consumer for the wild species (Table 7).

In addition to this statement, the TAR model had a better fit for farmed salmon and M-TAR for the wild-caught species. M-TAR fit better with a steep asymmetric adjustment, when increases tend to persist and decreases tend to revert quickly to the long-run relation (Enders and Granger 1998). The result obtained for cod is consistent with those found in another study (Jaffry 2004), where asymmetry has been reported with an M-TAR model for fresh hake produced and consumed in France. For this case too, asymmetry was operating in the same direction as wild cod, increases being passed on more rapidly than decreases to the consumer (with, respectively, $\rho_{1}=-0.239$ and $\rho_{2}=$ -0.352 ), but with a threshold $\tau=0$ in that case.

The difference between the farmed or wild origin of the products leads to an explanation in terms of supply uncertainty. Uncertainty is far more important for fishing than for aquaculture, whose control over production is higher (Anderson 2002). A decrease is more likely to be perceived as permanent in the farming sector and will be therefore transmitted to the consumer more rapidly than an increase which can be easily dealt with by an adjustment of supply. For the retailers, the decrease of the unit margin will be offset by an increase of sales.

Symmetrically, wild fish landings are subject to natural conditions and can be so chaotic (particularly groundfish species like North Atlantic cod-G. morhua - whose stock is severely depleted) that a decrease is seen as a transitory change in a structural context of excess demand or shortage of supply. Supermarkets are reluctant to pass on to consumers instantaneously a decrease of the upstream price because the whole supply chain may not be able to meet the requirements of the additional level of consumption. In this case, the retailers prefer to reduce the quantity on the market, sending a negative signal to the consumer. Indeed, the search costs must be considered as important adjustment costs in the fishing industry and motivate asymmetry in the price-through (Peltzman 2000).

This result has important implications for the CFP because conservation of natural stocks and market measures affect both supplies of wild-caught and farmed species. The 
production of wild species is bounded by the implementation of TAC defined yearly, or by the constraints of fishing capacity following some effort limitation measures or vessel limit decommissioning schemes. Within the CFP framework, fish prices may also be influenced by the COM defining floor prices below which the fish is withdrawn from the market or cannot be imported (see footnote 4 for salmon trade regulations on MIPs). EU imports of farmed Atlantic salmon from Norway were affected by the external trade policy of the EU during the 1990s and even after (MIPs, tariff duties). The EU represents one of the major markets for Norwegian exports competing with the domestic industry in Scotland or Ireland. Considering alleged dumping practices from the Norwegian industry, the European Council imposed an MIP to Norway at different periods of time between 1991 and 1999, period of the study. More recently, the European Council fixed a minimum price of $2.80 € / \mathrm{kg}$ between January 2006 and July 2008 (Council Regulation (CE) No $685 / 2008$ of 17 July 2008), as a substitute for previous customs tariffs ranging between $6.8 \%$ and $24.8 \%$. Such a policy had important consequences on the input price by creating market power on the supply side (Asche and Steen 2006). Any rigidity in the supply chain increases the adjustment costs for the intermediaries along the chain. Any release of such trade restrictions could very well be used by importers to expand their sales on the market by adjusting quantities, thus increasing market shares by passing the price decrease rapidly on to consumers.

We showed that the reduction of margins beyond a consistent threshold (e.g., because of high input prices) may trigger asymmetry in the transmission of price changes. The different EU policy measures and supply conditions influencing the trade of fishery products (mainly quotas and environmental conditions) and farmed products (mainly MIPs and trade restrictions) result in two opposite responses from the retailing industry regarding asymmetry. Because of the inelastic supply of fishery products, retailers are more likely to restore their margins by passing on input price increases more rapidly than decreases. Concerning farmed salmon whose supply is not limited, margins have a better chance to be recovered by a faster transmission of input price decreases whenever trade regulations allow it, thus increasing their sales, rather than a higher retail price that would reduce this highly elastic consumption (Asche et al 2002). Salmon is considered by supermarkets as a cheap product attracting seafood consumers. The regularity of supply in terms of quality, quantity, and price makes international trade of farmed salmon easier than that of fishery products. In the long run, the multiple retailers would adjust to a reduction of their gross margins through the quantity of farmed fish, and through prices regarding the wild-harvested species.

As far as the APT methodology is concerned, the extension of the TAR and MTAR models to consistent thresholds appears to be of great interest because there is no empirical or theoretical justification for looking for APT around a zero threshold. Indeed, the behavior of intermediaries may change according to the level of marketing margins. If the reduction of the margin is bearable in the short run, no particular asymmetric adjustment is required. Conversely, a too large reduction of the margin may appeal for different strategies.

The search costs, as long as they are measured around a consistent threshold, should then be considered as important adjustment costs to explain the asymmetric adjustment of prices along the food chain. The introduction of rigidity at the upstream level through various policy and regulations may affect the asymmetric behavior down the chain as 
long as no adjustment through quantity is made possible. The use of thresholds different from zero appears of great interest to analyze price transmission along the food supply chains in order to both evaluate the strategic behavior of intermediaries and appreciate the effects of policy measures on price transmission. Further analysis would be needed to see whether the same value of the threshold is observed for other food value chains and to possibly link this value to a strategic marketing behavior of multiple retailers.

In this paper, we showed that APT could be detected in market chains for two species of fish in the French market over a specific time period when product forms were relatively homogeneous. Analyses for subsequent years in the salmon supply chain were however not as conclusive. We attribute this inconclusiveness to the lack of equilibrium relationship between the price series due to the change of product forms (more fillets and less whole fish). The results of these subsequent analyses are shown in Table A2 (Appendix). Another fruitful area of analysis would therefore be an exploration of techniques that permit the detection of APT in the presence of structural changes.

\section{ACKNOWLEDGMENTS}

The authors would like to thank two anonymous reviewers and James R. Wilson, co-editor of the Canadian Journal of Agricultural Economics, for their very stimulating and helpful comments. This paper has received the support of the European Commission for the Salmar project (QLK5CT1999-01346). It does neither necessarily reflect its views nor its policy on this subject.

\section{REFERENCES}

Abdulai, A. 2002. Using threshold cointegration to estimate asymmetric price transmission in the Swiss pork market. Applied Economics 34: 679-87.

Anderson, J. L. 2002. Aquaculture and the future: Why fisheries economists should care. Marine Resource Economics 17: 133-51.

Asche, F., O. Flaaten, J. R. Isaksen and T. Vassdal. 2002. Derived demand and relationships between prices at different levels in the value chain; a note. Journal of Agricultural Economics 53 (1): 101-107.

Asche, F. and F. Steen. 2006. When anti-dumping measures lead to increased market power: A case study of the European salmon market. CEPR Discussion Paper No. 5781. London: Centre for Economic Policy Research.

Azzam, A. M. 1999. Asymmetry and rigidity in farm-retail price transmission. American Journal of Agricultural Economics 59: 570-72.

Bailey, D. and B. W. Brorsen. 1989. Price asymmetry in spatial fed cattle markets. Western Journal of Agricultural Economics 14: 246-52.

Boswijk, H. P. and J.-P. Urbain. 1997. Lagrange-multiplier tests for weak exogeneity: A synthesis. Econometric Reviews 16: 21-38.

Brorsen, B. W., J.-P. Chavas, W. R. Grant and L. D. Schnake. 1985. Marketing margins and price uncertainty: The case of the US wheat market. American Journal of Agricultural Economics 67: 521-28.

Carlton, D. W. 1989. The theory and the facts of how markets clear: Is industrial organization valuable for understanding macroeconomics? In Handbook of Industrial Organization, Vol. 1, edited by R. Schmalensee and R. Willig, pp. 909-46. Amsterdam: North-Holland Press.

Chan, K. S. 1993. Consistency and limiting distribution of the least squares estimator of a threshold autoregressive model. The Annals of Statistics 21: 520-33. 
von Cramon-Taubadel, S. 1998. Estimating asymmetric price transmission with the error correction representation: An application to the German pork market. European Review of Agricultural Economics 25: 1-18.

Dickey, D. A. and W. A. Fuller. 1979. Distribution of the estimators for autoregressive time series with a unit root. Journal of the American Statistical Association 74 (366): 427-31.

Dickey, D. A. and W. A. Fuller. 1981. Likelihood ratio statistics for autoregressive time series with a unit root. Econometrica 49 (4): 1057-72.

Eckert, A. 2002. Retail price cycles and response asymmetry. Canadian Journal of Economics 35 (1): 52-77.

Elliott, G., T. J. Rothenberg and J. H. Stock. 1996. Efficient tests for an autoregressive unit root. Econometrica 64: 813-36.

Enders, W. and C. W. J. Granger. 1998. Unit-root tests and asymmetric adjustment with an example using the term structure of interest rates. Journal of Business and Economic Statistics 16: 304-21.

Enders, W. and P. L. Siklos. 2001. Cointegration and threshold adjustment. Journal of Business and Economic Statistics 19: 166-76.

Engle, R. F. and C. W. J. Granger. 1987. Co-integration and error correction: Representation, estimation and testing. Econometrica 55 (2): 251-76.

Frey, G. and M. Manera. 2007. Econometric models of asymmetric price transmission, Journal of Economic Surveys 21 (2): 349-415.

Griffith, G. R. and N. E. Piggott. 1994. Asymmetry in beef, lamb and pork retail price transmission in Australia. Agricultural Economics 10: 307-16.

Guillotreau, P. (ed.) 2003. Prices and Margins Along the European Seafood Value Chain. Cahiers de l'Artemis 4: University of Nantes.

Guillotreau, P., L. Le Grel and M. Simioni. 2005. Price-cost margins and structural change: Subcontracting within the salmon marketing chain. Review of Development Economics 9 (4): 581-97.

Hall, A. 1994. Testing for a unit root in time series with pretest data-based model selection. Journal of Economic and Business Statistics 12: 461-70.

Heien, D. M. 1980. Markup pricing in a dynamic model of the food industry. American Journal of Agricultural Economics 62: 11-18.

Houck, J. P. 1977. An approach to specifying and estimating non reversible functions. American Journal of Agricultural Economics 59: 570-72.

Jaffry, S. 2004. Asymmetric price transmission: A case study of the French Hake value chain, Marine Resource Economics 19 (4): 511-24

Kinnucan, H. W. and O. D. Forker. 1987. Asymmetry in farm retail price transmission for major dairy products. American Journal of Agricultural Economics 69: 285-92.

Le Grel, L., F. Asche, J. Cruz Filipe, F. Guia, P. Guillotreau, J. Setälä, K. Saarni, A. Honkanen and J. Virtanen. 2003. Empirical effects of EU regulations on trade and production of fishery products. In Prices and Margins along the Seafood Value Chain, edited by P. Guillotreau, pp. 135-63. Cahiers de l'Artemis 4: University of Nantes.

Meyer, J. and S. von Cramon-Taubadel. 2004. Asymmetric price transmission: A survey. Journal of Agricultural Economics 55 (3): 581-611.

Peltzman, S. 2000. Prices rise faster than they fall. Journal of Political Economy 108 (3): 466-502.

Schwert, G. W. 1989. Tests for a unit roots: A Monte-Carlo investigation. Journal of Economic and Business Statistics 7: 147-49.

Ward, R. W. 1982. Asymmetry in retail, wholesale, and shipping price point pricing for fresh vegetables. American Journal of Agricultural Economics 64: 205-12.

Wolffram, R. 1971. Positivistic measures of aggregate supply elasticities: Some new approachessome critical notes. American Journal of Agricultural Economics 53: 342-52.

Wohlgenant, M. K. 1985. Competitive storage, rational expectations and short run food price determination. American Journal of Agricultural Economics 67: 739-48. 
Wohlgenant, M. K. 2001. Marketing margins: Empirical analysis. In Handbook of Agricultural Economics, Vol. 1B, edited by B. L. Gardner, L. Bruce and G. C. Rausser, pp. 933-70. Amsterdam: North Holland Press.

Worth, T. 1999. The F.O.B.-retail price relationship for selected fresh vegetables. Vegetables and Specialties 279: 26-31.

\section{APPENDIX}

Table A1. Results of the ADF and DF-GLS unit root tests for salmon (January 1998-April 2009)

\begin{tabular}{|c|c|c|c|c|c|}
\hline \multirow[b]{2}{*}{ Variable } & \multicolumn{3}{|c|}{ ADF test } & \multicolumn{2}{|c|}{ DF-GLS } \\
\hline & $\begin{array}{l}\text { No constant, } \\
\text { no trend }\end{array}$ & $\begin{array}{l}\text { Constant } \\
\text { trend }\end{array}$ & $\begin{array}{l}\text { Constant, } \\
\text { and trend }\end{array}$ & $\begin{array}{c}\text { Constant, } \\
\text { no trend }\end{array}$ & $\begin{array}{l}\text { Constant, } \\
\text { and trend }\end{array}$ \\
\hline $\begin{array}{l}\text { Price of fresh } \\
\text { salmon } \\
\text { imported from } \\
\text { Norway }\end{array}$ & $\begin{array}{c}-0.173 \\
(\operatorname{lags}=5)\end{array}$ & $\begin{array}{c}-2.383 \\
(\operatorname{lags}=5)\end{array}$ & $\begin{array}{c}-2.352 \\
(\operatorname{lags}=5)\end{array}$ & $\begin{array}{c}-2.382^{*} \\
(\operatorname{lags}=5)\end{array}$ & $\begin{array}{c}-2.423 \\
(\operatorname{lags}=5)\end{array}$ \\
\hline $\begin{array}{l}\text { French retail price } \\
\text { of fresh salmon }\end{array}$ & $\begin{array}{c}0.787 \\
(\operatorname{lags}=16)\end{array}$ & $\begin{array}{c}-1.316 \\
(\operatorname{lags}=16)\end{array}$ & $\begin{array}{c}-2.518 \\
(\operatorname{lags}=14)\end{array}$ & $\begin{array}{c}0.439 \\
(\operatorname{lags}=16)\end{array}$ & $\begin{array}{c}-2.493 \\
(\operatorname{lags}=14)\end{array}$ \\
\hline
\end{tabular}

Notes: ${ }^{1}$ Series are expressed in logarithm.

${ }^{2}$ Statistical significance is indicated by a single asterisk $(*)$ for the $10 \%$ level and a double asterisk $\left.{ }^{* *}\right)$ for the $5 \%$ level.

Table A2. Estimates of price transmission in the salmon value chain (January 1998-April 2009)

\begin{tabular}{lccccc}
\hline & Engle-Granger & TAR & M-TAR & Threshold-TAR & Threshold-M-TAR \\
\hline$\rho_{1}$ & -0.105 & -0.019 & 0.020 & 0.033 & 0.217 \\
& $(-1.786)^{1}$ & $(-0.247)$ & $(0.236)$ & $(0.363)$ & $(1.907)$ \\
$\rho_{2}$ & $\mathrm{NA}$ & -0.199 & -0.201 & -0.182 & -0.181 \\
& & $(-2.501)^{2}$ & $(-2.726)$ & $(-2.602)$ & $(-2.958)$ \\
Lags & 5 & 5 & 5 & 5 & 5 \\
$\tau$ & $\mathrm{NA}$ & 0 & 0 & 0.116 & 0.062 \\
AIC $^{3}$ & -2.471 & -2.481 & -2.492 & -2.488 & -2.540 \\
\hline
\end{tabular}


Table A2. Continued

\begin{tabular}{lcrrcc}
\hline & Engle-Granger & TAR & M-TAR & Threshold-TAR & Threshold-M-TAR \\
\hline SIC $^{3}$ & -2.340 & -2.326 & -2.338 & -2.333 & -2.385 \\
$\Phi^{4,5}$ & NA & 3.128 & 3.865 & 3.590 & 7.052 \\
$\rho_{1}=\rho_{2}{ }^{6}$ & NA & 3.015 & 4.451 & 3.917 & 10.666 \\
\hline
\end{tabular}

Notes: ${ }^{1}$ Entries in this row are the $t$-statistics for the null hypothesis $\rho_{1}=0$. Note that $\rho_{1}=\rho_{2}=\rho$ when following the Engle-Granger methodology (second column).

${ }^{2}$ Entries in this row are the $t$-statistics for the null hypothesis $\rho_{2}=0$.

${ }^{3} \mathrm{AIC}$ and SIC denote the Akaike and the Schwarz criterions. The AIC and SIC are computed as: $-2 L / T+2 K / T$, and $-2 L / T+K \log (T) / T$, respectively, where $L$ denotes the likelihood and $K$ is the number of regressors in the estimated model.

${ }^{4}$ Entries in this row and in the third and fourth columns are the sample values of the TAR and M-TAR $\Phi$-statistics. Critical values for TAR $\Phi$ for a two variable case and one lagged change are approximately $4.99,6.01$, and 8.30 for $10 \%, 5 \%$, and $1 \%$, respectively. The corresponding values for M-TAR $\Phi$ are approximately 5.47, 6.51, and 8.65. See table 1 in Enders and Siklos (2001).

${ }^{5}$ Entries in this row and in the fifth and sixth columns are the sample values of the TAR-consistent and M-TAR-consistent $\Phi$-statistics. Critical values for TAR-consistent $\Phi$ for a two variable case and one lagged change are approximately $6.02,7.08$, and 9.51 for $10 \%, 5 \%$, and $1 \%$, respectively. The corresponding values for M-TAR-consistent $\Phi$ are approximately 5.76, 6.86, and 9.29. See table 6 in Enders and Siklos (2001).

${ }^{6}$ Entries in this row are the sample $F$-statistics for the null hypothesis that the adjustment coefficient is equal. Significance levels are in parentheses below. 